\title{
Editorial
}

Wolfgang Holzgreve

\section{Some historical and general considerations on NIPT - great progress achieved, but we have to proceed with caution}

https://doi.org/10.1515/jpm-2021-0436

\section{Background}

Ever since we have recordings in history of human thoughts and emotions there is evidence for concern of expectant parents regarding the health of their unborn child. In the past, however, the ability to find out whether the growing fetus had problems in its development was very limited. Especially in the 70s this changed with the introduction of diagnostic ultrasound which allowed to visualize the features of the unborn child without harm, and around the same time biochemical marker screening approaches were developed for the prediction of neural tube defects or chromosomal anomalies in the fetus.

The improvements of the ultrasound technology quickly allowed amniocentesis to be performed around 16 weeks of pregnancy and since the middle of the $80 \mathrm{~s}$ chorionic villus biopsy at around 10 weeks of gestation [1] Ultrasound will most likely never be fully replaced in pregnancy surveillance by genetric techniques, because the majority of the structural defects to be detected prenatally which constitute the majority of the $2-4 \%$ congenital anomalies, are multifactorial (e.g. cardiac or neural tube defects) but the new powerful screening tests have to be combined in a logical and affordable way [2].

\section{Development}

Cultures from amniotic fluid or chorionic villus cells enabled cytogenetic analysis, and prenatal diagnosis of trisomy 21 was offered to women with an age of 35 years

Corresponding author: Wolfgang Holzgreve, Professor, Medical Director and CEO, Chair of the Foundation for the Child with Handicap, Obstetrics and Gynecology, University Hospital Bonn, VenusbergCampus 1 Gebäude 1, 53127, Bonn, Germany,

E-mail: wolfgang@holzgreve.net and older because of their increased risk for fetal aneuploidies so regularly that unfortunately and wrongly this offer almost became for many synonymous with "Prenatal Diagnosis" in general. From the beginning, however, the ability to have a legal termination of pregnancy based on a prenatal diagnosis raised the serious conflict between the fundamental prohibition of actively ending any human life based on the concept of dignity of every (born and unborn) human being on the one side and the autonomy of the pregnant woman on the other. This basic conflict ultimately cannot be solved in any absolutely satisfactory way, and different countries found various solutions (Cathy Bilardo [3] in this issue). For a majority in many populations a way to deal with this dilemma is to institute knowledgeable and empathetic counselling about the facts of prenatal diagnosis and its consequences so that women can make their own informed choices within the legal limits of their society. This important issue is one of the cores of this special edition of the Journal of Perinatal Medicine for which I am very thankful to the publisher thus allowing the presentations to be printed from a wellattended and positively received Symposium, which was conducted together with the Foundation for the Handicapped Child in Bonn, Germany in December 2020. The ethical aspects of NIPT are elegantly discussed in this issue by Annette Dufner [4], Bert Heinrichs [5], Christoph Rehmann-Sutter [6], Bettina Schoene-Seifert and Chiara Junker [7], Peter Miny et al. [8] and Klaus Zerres et al. [9], and the legal ones by Stephan Huster [10]. Since dealing with dilemma and complicated alternatives for decision can cause significant stress during pregnancy, the awareness of maternal stress, the consequences for the offspring and the need for intervention to decrease stress resilience is discussed in a comprehensive way by Birgit Arabin et al. [11] in this issue. It is my point of view that the ethical considerations on significant new developments in medicine such as NIPT should not follow their introduction into clinical practice but they should proceed them [12].

A well-known problem of prenatal medicine from the beginning was the fact that in the majority of cases the 
prenatally diagnosed chromosomal and metabolic diseases could not be treated, and therefore Sir William Liley, one of the pioneers in this field, even spoke about a "search and destroy" mission. He was, however, at the same time "the father" of prenatal therapy, because following the ability to assess by amniocentesis and blood sampling in utero the severity of a Rhesus blood group incompatibility, he developed techniques for treating the affected babies prenatally by intrauterine blood transfusion with the delicate technique of fetoscopy. Therefore obtaining just a precise diagnosis mutated into effective though risky prenatal therapy and followed this way in the general principle in medicine that accurate diagnosis should not be considered as the ultimate goal, but as the necessary prerequisite for an appropriate prenatal therapy. In order to highlight this positive development already in 1987 I gave a book about these newly developing techniques the title "Prenatal Medicine" rather than just "Prenatal diagnosis" [13].

In the meantime fetal Rhesus D antigen genotyping in D-negative mothers is one of the many positive examples of applying Non-invasive Prenatal Testing in clinical practice [14]. The traditional approach of administering anti D immmunoglobuline to all D-negative mothers is needless in the $40 \%$ of pregnancies with a D-negative fetus. Noninvasive fetal $\mathrm{D}$ antigen genotyping not only avoids an unnecessary discomfort and exposure to blood products but is also cost saving and has been successfully introduced in a number of countries including Germany [15] thus illustrating the significant and consequential progress achieved by NIPT.

Although prenatal diagnosis was looked at sceptically in some parts of the general population from the beginning, it was soon confirmed that it has saved many lives of unborn children, because less often than before by these technological advances women with anxieties could be calmed based on the proper prenatal diagnosis, e.g. in cases of an in utero rubella virus infection or when they became pregnant with advanced maternal age. Regarding genetic diseases with Mendelian patterns of inheritance Bernadette Modell showed that in populations with increased risk for Beta-thalassemia in the UK after the proper counseling about the $25 \%$ recurrence risk, the pregnancy rates went down dramatically, whereas it increased to normal again after the possibility of prenatal diagnosis even by the invasive method of fetoscopic blood sampling [16].

Another burden on prenatal diagnosis by amniocentesis or CVS always was the low, but definitely existing risk of harming the pregnancy by the prenatal invasive sampling procedure [17]. Therefore since the 70 s there was an intense search for a non-invasive method of prenatal diagnosis, and in a collective effort of international research first the isolation of fetal cells from the blood of pregnant women was tried whereas later this method became successful and clinically mature by looking at cellfree DNA in the maternal blood. Because progress in medicine through publications, lectures and media travels fast these days, now more than 10 million cases have been investigated noninvasively by the NIPT methodology.

\section{Ethical and legal concern}

In ethical terms, Non-invasive Prenatal Testing (NIPT) is a major breakthrough and progress for the women concerned and even helps to understand better pregnancyrelated diseases such as preclampsia and autoimmune diseases [18], but not surprisingly the general discussion about the justification for prenatal diagnosis of untreatable conditions started immediately again when this progress on non-invasive testing became available. To a great extent the important discussion about the general justification for prenatal diagnosis was, from my point of view, sometimes mixed up with the progress of the noninvasive over the invasive techniques, and these considerations are presented thoughtfully and elegantly in the manuscripts of this special issue of the JPM.

If we look into the fascinating history of prenatal diagnosis in more detail we recognize remarkable progress in prenatal screening and diagnosis within a relatively short time e.g. that after maternal age was for a long time the only parameter used to define a population at risk in pregnancy, the observation of lower maternal serum alphafetopotein (AFP) levels being associated with trisomy 21 in populations screened for neural tube defects initiated a systematic search for other biochemical markers in the maternal blood suitable to assess the risk for common trisomies. Using AFP, free $\beta$-human chorion gonadotropin (hCG), and unconjugated estriol ("triple test"; sometimes complemented by other markers) in the second trimester of pregnancy multi-parameter maternal serum testing became the recommended and widely used approach to assess an individual risk for fetal trisomies. A further significant increase in sensitivity was achieved by including the extension of the skin in the fetal neck (nuchal translucency) as determined by ultrasound in the first trimester of pregnancy and the simultaneous measurement of hCG and the pregnancy associated plasma protein A (PAPP-A), known as the first trimester or combined test. Various additional serum and ultrasound markers as well as testing approaches were proposed [19], but the major step forward 
in screening was the development of NIPT which is now by far the best screening method together with applying ultrasound.

The introduction of NIPT is a positive example for how a new technology should be introduced into clinical practice, that is after the research and development after careful planning [20] the proper trials were performed [21-23]. So that the public was prevented from an immature technical approach spreading into clinical use without rigorous evaluation.

Apart from the prenatal diagnosis of trisomies [24, 25] the detection of fetal sequence variants in cffDNA not present in the mother is now reliably feasible by a variety of techniques such as RTQ-PCR, digital PCR and more recently HTS and applicable for a number indications such as paternally inherited dominant conditions or autosomal recessive conditions with different mutations in both parents as well as new mutations [26]. Testing for example of FGFR3 (achondroplasia, thanatophoric dysplasia) or FGFR2 (Apert syndrome) is a non-invasive diagnostic option with suspicious ultrasound findings when the parents are phenotypically normal [27]. The diagnostic approach of course is more challenging in recessive conditions when both parents carry the same mutation as well as for maternal dominant disorders or X-linked conditions when the mother is a carrier. Two approaches have been applied to address these situations: The relative mutation dosage as assessed by droplet digital PCR (ddPCR) reflects slight differences in the ratio of mutant and wildtype alleles in the cfDNA depending on the presence of absence of mutant alleles in the cffDNA. The second strategy is HTS-based genome-wide SNP-genotyping and the assessment of relative haplotype dosage in theory permitting the testing of virtually any monogenic condition [28]. This indirect testing approach uses SNP haplotypes linked to a specific locus of interest and is reliable due to the abundancy of available SNPs. For prenatal diagnosis the paternal haplotype in the cfDNA is detected by the analysis of SNPs homozygous in the mother (AA) and heterozygous in the father (AC). The statistical significance of any allelic imbalance is calculated by a sequential probability ratio test (SPRT). Obviously, the parental coupling phase (i.e. the haplotype linked to the mutation) has to be known e.g. by testing family members in one or both. The genomewide approach can by customized by recent targeted capture sequencing technologies to restrict sequencing to genomic regions of interest [29]. An alternative approach was proposed by Dan et al. [30] by searching for known or denovo variants following HTS based non-invasive targeted capture sequencing of cfDNA and both parents. This was identified e.g. causative mutations in three affected families following the sonographic suspicion of a skeletal dysplasia analysing a panel of 16 genes of interest. The most recent progress of NIPT for chromosomal anomalies and single gene anomalies is presented elegantly in this issue by Alexander Scharf and Samantha Leonhard [31], respectively.

\section{Conclusions}

So NIPT in addition to being a reliable method for the prenatal detection of chromosomal anomalies, microdeletions is becoming a valid option for a growing number of monogenic conditions. Some of the approaches are rather complex, however, and it remains to be seen what parents and health care systems with an insurance based solidarity principle are ready to invest in order to avoid the risk of an invasive procedure allowing simple and accurate testing. These medico-legal questions are also addressed in this special issue of the Journal of Perinatal Medicine where we want to be updated on the most recent developments in NIPT on the one side, and to raise the ethical and legal considerations about its justifications, risks and potential side effects in an open and knowledgeable way on the other side without claiming to have the perfect answers to all the serious questions.

Since fortunately the progress in prenatal diagnosis, which for a long time was moving way ahead of the possibilities in prenatal therapy, now is bridging the gap with significant achievements in prenatal therapy such an intrauterine surgery or gene therapy [32].

Our genetic counselling, which has the aim of allowing women to make their own decision based on proper and up to date information, constantly has to be updated based on the progress in this dynamic field of medicine [33]. The so-called "Information consent" has to be thrieved for, but it is always a challenge for counsellors to make sure that counselees can understand the complex information and statistics and can ultimately make decisions in accordance with their own beliefs and judgement [34]. For example, the new option of gene therapy has to be taken into account in those genetic conditions of the fetus, which now can be treated much better such as haemophilia by factor substitution, innovative medicines or gene therapy. This example of progress in gene therapy is therefore also covered in this special edition on NIPT by Johannes Oldenburg.

Overall, since the number of invasive procedures has greatly been reduced by NIPT, this technique has saved many fetal losses caused by invasive procedures, although there risk of amniocentesis and CVS is probably low now in experienced hands. The fascinating development of NIPT 
is an example that significant progress in the laboratory after rigorous testing in the general population can enter clinical routine and in this way NIPT has improved the choices significantly for women and couples in a sensitive area of medicine- but we always have to proceed with caution.

Research funding: None declared.

Author contributions: Single author contribution. Competing interests: Author states no conflict of interest.

\section{References}

1. Holzgreve W, Miny P. Chorionic villus sampling and placental biopsy. In: James DK, Steer PJ, Weiner CP, Gonik B, editors. High risk pregnancy, 2nd ed. Philadelphia: Saunders; 1999:207-14 pp.

2. Holzgreve W. Will ultrasound-screening and ultrasound-guided procedures be replaced by non-invasive techniques for the diagnosis of fetal chromosome anomalies? Ultrasound Obstet Gynecol 1997;9:217-9.

3. Bilardo $\mathrm{CM}$. The implementation of non-invasive prenatal testing (NIPT) in the Netherlands. J Perinat Med 2021;49:941-4.

4. Dufner A. Non-invasive prenatal testing (NIPT): does the practice discriminate against persons with disabilities? J Perinat Med 2021;49:945-8.

5. Heinrichs B. Moral ambivalence. A comment on non-invasive prenatal testing from an ethical perspective. J Perinat Med 2021; 49:949-52.

6. Rehmann-Sutter C. Should prenatal screening be seen as 'selective reproduction'? four reasons to reframe the ethical debate. J Perinat Med 2021;49:953-8.

7. Schoene-Seifert B, Junker C. Making use of non-invasive prenatal testing (NIPT): rethinking issues of routinization and pressure. J Perinat Med 2021;49:959-64.

8. Filges I, Miny P, Holzgreve W, Tercanli S. How genomics is changing the practice of prenatal testing. J Perinat Med 2021;49: 1003-1003.

9. Zerres K, Rudnik-Schöneborn S, Holzgreve W. Do non-invasive prenatal tests promote discrimination against people with Down syndrome? what should be done? J Perinat Med 2021;49: 965-71.

10. Huster S. Non-invasive prenatal diagnostics (NIPD) in the system of medical care. Ethical and legal issues. J Perinat Med 2021;49: 972-8.

11. Arabain B. Awareness of maternal stress, consequences for the offspring. J Perinat Med 2021;49:979-89.

12. Holzgreve W. Ethik in der pränatalen Medizin - geht sie voran oder läuft sie hinterher? Ther Umsch 2006;63:681-2.

13. Holzgreve W. Pränatale Medizin. Heidelberg - New York: SpringerVerlag; 1987:186 p.

14. Zhong XY, Holzgreve W, Hahn S. Detection of fetal rhesus D and sex using fetal DNA from maternal plasma by multiplex polymerase chain reaction. Br J Obstet Gynaecol 2000;107: 766-9.

15. Eiben B, Keck C, Kozlowski P. G-BA Anmerkungen zu den neuen Mutterschafts-Richtlinien (NIPT RhD), Frauenarzt 2021;156:156-7.
16. Modell B, Kulier AM, Wagner M. Community genetic services in Europe: report on survey; 1991.

17. Holzgreve W, Tercanli S, Surbek D, Miny P. Invasive diagnostic methods. In: Rodeck C, Whittle MJ, editors. Fetal medicine: basic science and clinical practice, 2nd ed. Churchill Livingstone Publishers; 2006:417-33 pp.

18. Holzgreve W, Miny P, Zhong XY, Lapaire O, Tercanli S, Diesch C, et al. Genetic communication between fetus and mother: short and longterm consequences. Am J Obstet Gynecol 2007;196:372-81.

19. Holzgreve W. Prenatal screening and diagnosis. Section editor für das Buch: Fetal Medicine: Basic Science and Clinical Practice. Herausgegeben von C. Rodeck und M. Whittle. Edinburgh: Churchill Livingstone; 2000:1162 p.

20. Holzgreve W, Garritsen HSP, Tercanli S, Miny P, Nippert I, Gänshirt-Ahlert D. Noninvasive prenatal diagnosis. Strategy for a clinical trial. In: Simpson JL, Elias S, editors. Annals of the New York Academy of Sciences. New York: The New York Academy of Sciences; 1994, vol 731:253-6 pp.

21. Holzgreve W, Hahn S. Fetal diagnosis. In: Cooper DN, editor. Encyclopedia of the human genome. Nature Publishing Group; 2003, vol 2:477-80 pp.

22. Bianchi DW, Simpson JL, Jackson LG, Elias S, Holzgreve W, Evans MI, et al. Fetal gender and aneuploidy detection using fetal cells in maternal blood: analysis of NIFTY I data. Prenat Diagn 2002;22: 609-15.

23. Bischoff FZ, Hahn S, Johnson KL, Simpson JL, Bianchi DW, Lewis $\mathrm{DE}$, et al. Intact fetal cells in maternal plasma: are they really there? Lancet 2003;361:139-40.

24. Lo YM, Corbetta N, Chamberlain PF, Rai V, Sargent IL, Redman CW, et al. Presence of fetal DNA in maternal plasma and serum. Lancet 1997;350:485-7.

25. Zimmermann B, Levett L, Holzgreve W. Use of real-time polymerase chain reaction for the detection of fetal aneuploidies. Methods Mol Biol 2006;336:83-100.

26. Zhong XY, Hahn S, Holzgreve W. Prenatal identification of fetal genetic traits. Lancet 2001;357:310-1.

27. Chitty LS, Mason S, Barrett AN, Lench N, Daley R, Jenkins LA. Noninvasive prenatal diagnosis of achondroplasia and thanatopheric dysplasia, next-generation sequencing allows for a safer more accurate and comprehensive approach. Prenat Diagn 2015;35: 656-62.

28. Lo YM, Chan KCA, Sun H, Chen EZ, Jiang P, Lun FMF, et al. Maternal plasma DANN sequencing reveals the genome - wide Genetic and mutational profile of the fetus. Sci Transl Med 2010;2:Glra 91.

29. Hudecova I, Chief RWK. Non-invasive prenatal diagnosis of thalassemias unsing maternal plasma cell free DNA. Best Pract Res Clin Obstet Gynaecol 2017;39:63-73.

30. Dan S, Yuan Y, Wang Y, Chen C, Gao C, Yu S. Non-invasive prenatal diagnosis of lethal skeletal dysplasia by targeted capture sequencing of maternal plasma. PloS One 2016;11:e0159355.

31. Leonard SJ. Reproductive genetic screening for information: evolving paradigms? J Perinat Med 2021;49:998-998.

32. Harrison M, Evans M, Adzick S, Holzgreve W. The unborn patient, 3. völlig überarbeitete Auflage. Philadelphia: Harcourt Health Science, Saunders; 2001:709 p.

33. Holzgreve W. Fetal anomalies - from prenatal diagnosis to therapy. J Perinat Med 2018;46:951-2.

34. Faden RR, Beauchamp TL. A history and theory of informed consent. New York: Oxford University Pr.; 1986. 